\title{
Decolorization of a Corn Fiber Arabinoxylan Extract and Formulation of Biodegradable Films for Food Packaging
}

\author{
Verónica Weng ${ }^{1}$, Carla Brazinha ${ }^{1}\left(\mathbb{D}\right.$, Isabel M. Coelhoso ${ }^{1}(\mathbb{D})$ and Vitor D. Alves ${ }^{2, *(D)}$ \\ 1 LAQV-REQUIMTE, Department of Chemistry, NOVA School of Science and Technology, FCT NOVA, \\ Universidade Nova de Lisboa, 2829-516 Caparica, Portugal; v.weng@campus.fct.unl.pt (V.W.); \\ c.brazinha@fct.unl.pt (C.B.); imrc@fct.unl.pt (I.M.C.) \\ 2 LEAF-Linking Landscape, Environment, Agriculture and Food, Instituto Superior de Agronomia, \\ Universidade de Lisboa, Tapada da Ajuda, 1349-017 Lisboa, Portugal \\ * Correspondence: vitoralves@isa.ulisboa.pt
}

Citation: Weng, V.; Brazinha, C.; Coelhoso, I.M.; Alves, V.D.

Decolorization of a Corn Fiber Arabinoxylan Extract and Formulation of Biodegradable Films for Food Packaging. Membranes 2021, 11, 321. https://doi.org/10.3390/ membranes11050321

Academic Editor: Fabrice Gouanvé

Received: 8 April 2021

Accepted: 26 April 2021

Published: 28 April 2021

Publisher's Note: MDPI stays neutral with regard to jurisdictional claims in published maps and institutional affiliations.

Copyright: (C) 2021 by the authors. Licensee MDPI, Basel, Switzerland. This article is an open access article distributed under the terms and conditions of the Creative Commons Attribution (CC BY) license (https:// creativecommons.org/licenses/by/ $4.0 /)$.

\begin{abstract}
Corn fiber from the corn starch industry is a by-product produced in large quantity that is mainly used in animal feed formulations, though it is still rich in valuable components, such as arabinoxylans, with proven film-forming ability. During arabinoxylans' recovery under alkaline extraction, a dark-colored biopolymer fraction is obtained. In this work, a purified arabinoxylan extract from corn fiber with an intense brownish color was decolorized using hydrogen peroxide as the decolorizing agent. Biodegradable films prepared by casting the decolorized extract exhibited a light-yellow color, considered more appealing, envisaging their application in food packaging. Films were prepared with glycerol as plasticizer and citric acid as cross-linker. Although the cross-linking reaction was not effective, films presented antioxidant activity, a water vapor permeability similar to that of non-decolorized films, and other polysaccharides' and mechanical properties that enable their application as packaging materials of low-water-content food products.
\end{abstract}

Keywords: corn fiber; arabinoxylan; decolorization; biodegradable films; food packaging

\section{Introduction}

Petroleum-based plastics are widely used and still play an important role as packaging materials and to produce a broad range of objects for our daily life, especially due to their unique properties and low production costs. There is, however, a rising concern in an environmental and ecological perspective since they are very resistant to degradation, including biodegradation, are often non-recyclable, and their burning as a way of disposing also releases toxic gases to the atmosphere, contributing to air pollution and global warming [1].

An approach to balance this high dependency on petroleum-based plastics is by exploring alternative ways, which can include the use of biodegradable polymers. According to the European Bioplastics Organization [1], biodegradable polymers may be bio-based, which include polymers extracted from biomass (polysaccharides and proteins), polymers produced by microorganisms (e.g., polyhydroxyalkanoates, polysaccharides), and polymers synthesized with microbial monomers (e.g., polylactic acid). In addition, there are also oil-based biodegradable polymers, such as polycaprolactone, poly(butylene succinate) (PBS) and its copolymers, and poly(butylene adipate-co-terephthalate) (PBAT) [2,3]. Though all mentioned polymer categories are usually referred to be biodegradable, only some of them, which include natural biopolymers from biomass-like polysaccharides, may be degraded by microorganisms under a wide range of environments (seawater, fresh water, soil, home and industrial composting, sewage sludge, and landfill) [4].

Polysaccharides are an important and diverse class in biopolymers, which can be found in great abundance in nature. Membranes produced from polysaccharides have good potential to be applied in the food industry as packaging or coatings. They are usually 
good barriers against gases like oxygen and carbon dioxide and have moderate mechanical properties. However, due to their hydrophilic nature, they show a low barrier against water vapor and a high water absorption and solubility in liquid water [3].

A wide range of polysaccharide-based membranes has been developed over the years, including the optimization of their functional properties to be used as packaging materials. Several strategies were developed, such as the addition of plasticizers, cross-linking agents, bioactive compounds, and lipids [5,6]. Some polysaccharides used include pectin, starch, cellulose, alginate, chitosan, and microbial polysaccharides (FucoPol) [3,7]. As examples, composite pectin-cocoa butter films were prepared with glycerol as a plasticizer, presenting the potential for food applications [8]. Films of starch from cassava residues, reinforced with modified cellulose nanocrystals, and glycerol as a plasticizer were also produced [9]. Antioxidative and antimicrobial chitosan films were obtained with the incorporation of leaf, stem, and seed extract from Pistacia terebinthus and glycerol as a plasticizer [10]. Films from FucoPol produced with Enterobacter $A 47$ were obtained using citric acid as cross-linker [11]. Chitosan with different nanofillers enhanced the barrier and mechanical properties of the films for food packaging [12].

Food processing industries result in several low-valued by-products, which are usually considered as waste or used as animal feed. However, most of these residues still contain in their composition compounds with interesting properties [13,14]. An example of these byproducts is corn fiber from the corn starch industry that is mainly incorporated in animal feed. However, it is composed of ferulic acid, a phenolic compound with antioxidant activity and arabinoxylan with film-forming properties. Therefore, there is interest in the valorization of both components [13,15].

Arabinoxylans are polysaccharides found in cereal grains like corn/maize, wheat, oats, barley, rice, sorghum, and rye [16,17]. They are constituted by a linear backbone of $\beta$-(1,4)-xylopyranosyl, which can be substituted with $\alpha$-L-arabinofuranosyl residues in both O-3 and O-2 positions, only O-3, only O-2, or simply not have any substituents. These arabinose substituents can then be found esterified in O-5 with ferulic acid. The amount and distribution of arabinose residues, as well as the content of ferulic acid in the polysaccharide, vary with the origin and extraction method. Additionally, arabinoxylans can be classified according to their solubility in water as water-extractable and water-unextractable. Due to cross-linking reactions between arabinoxylan and cell wall components, a portion of this polysaccharide is water insoluble. Therefore, to recover these fractions, usually, an alkaline extraction is applied to hydrolyze these linkages [18].

Purification methods are important to remove contaminants and obtain an extract rich in arabinoxylans. Some reported purification methods for arabinoxylan extracts include membrane processes, such as diafiltration in a hollow-fiber membrane [15] or dialysis, to remove low-molecular-weight contaminants [19].

In a previous work, a fraction enriched in arabinoxylans obtained by alkaline extraction from corn fiber was purified using membrane processes, and the obtained arabinoxylans were used to produce stand-alone films [15]. However, the films obtained were not transparent, presenting a brownish color, which may not be appealing if they are intended for food packaging. As such, in the present work, two different decolorization methods were explored to remove the color of the purified arabinoxylan extract, before using the polysaccharide fraction for films' production. In addition to that, citric acid was studied as cross-linking agent to enhance films' moisture resistance. Films were characterized in terms of color, solubility in water, water vapor permeability, mechanical properties, and antioxidant activity.

\section{Materials and Methods}

\subsection{Materials}

Arabinoxylan was obtained from alkaline extraction of corn fiber (with an aqueous solution of $0.25 \mathrm{M}$ of sodium hydroxide, under stirring at $30^{\circ} \mathrm{C}$ for $7 \mathrm{~h}$ ), and the extract was purified in a hollow-fiber membrane unit (UFP-100-C-5A, from GE Healthcare, Chicago, 
IL, USA), according to the procedure used by Serra et al., 2020 [15]. The purified extract was freeze-dried, and the solid was stored in a sealed plastic bag at $-20^{\circ} \mathrm{C}$. Activated charcoal (Sigma-Aldrich, St. Louis, MO, USA) and hydrogen peroxide (José Manuel Gomes dos Santos LDA, Odivelas, Portugal) were used for the decolorization process. For the formulation of films, glycerol (Sigma-Aldrich, USA) and citric acid (PanReac, Barcelona, Spain) were used. For antioxidant activity determination, sodium acetate (Riedel-de-Haën, Seelze, Germany), acetic acid glacial (Fisher Chemical, Loughborough, UK), TPTZ (2,3,5triphenyltetrazolium chloride) (Sigma-Aldrich, USA), HCl (Honeywell, Wien, Austria), and ferric chloride (PanReac, Spain) were used.

\subsection{Decolorization Process}

The decolorization of purified arabinoxylan extract was tested using two methods: adsorption by activated charcoal and reaction with hydrogen peroxide. In the first case, freeze-dried extract was used to prepare an arabinoxylan solution $(2 \% w / v)$ with deionized water to which activated charcoal was added $(0.5 \%$ or $2 \% w / v)$. The mixture was stirred for $1 \mathrm{~h}$ at room temperature and then filtered. Absorption spectra were measured before and after contact with activated charcoal using a spectrophotometer (Evolution 201, Thermo Scientific, Waltham, MA, USA).

When using hydrogen peroxide, the arabinoxylan solution $(2 \% w / v)$ was firstly heated up to $45{ }^{\circ} \mathrm{C}$ and hydrogen peroxide $\left(10 \% v / v_{\text {final }}\right)$ was added. The mixture was left at $45^{\circ} \mathrm{C}$ for $2 \mathrm{~h}$ under stirring and absorption spectra were measured before and after the reaction.

\subsection{Preparation of Films}

Films without decolorization were prepared by dissolving freeze-dried arabinoxylan (Ax) in deionized water $(2 \% w / v)$, to which glycerol $30 \%\left(w / w_{\text {Ax basis }}\right)$ was added as plasticizer. The mixture was stirred for $15 \mathrm{~min}$ and, afterwards, a volume of $10 \mathrm{~mL}$ was cast in 50-mm plastic Petri dishes. The Petri dishes were left for $24 \mathrm{~h}$ at $35^{\circ} \mathrm{C}$ and at a relative humidity of $30 \%$ for solvent drying. The films were peeled and stored in a desiccator at room temperature with a relative humidity of $62 \%$, until further characterization.

Films with decolorization were produced using the resulting solution from the decolorization method using hydrogen peroxide $\left(10 \% v / v_{\text {final }}\right)$. To this solution, glycerol $30 \%\left(w / w_{\text {Ax basis }}\right)$ and citric acid $10 \%\left(w / w_{\text {Ax basis }}\right)$ were also added, as plasticizer and cross-linking agents, respectively. The final mixture was cast and dried and the films were stored, as described previously. The effect of thermal treatment $\left(90^{\circ} \mathrm{C}, 1 \mathrm{~h}\right)$ on the cross-linking reactions was also studied for decolorized films. Overall, five different films were developed according to Table 1.

Table 1. Different conditions tested in the production of arabinoxylan (Ax) films, with decolorization process employing hydrogen peroxide, glycerol as plasticizer, citric acid as cross-linker, and heat treatment at $90^{\circ} \mathrm{C}$.

\begin{tabular}{cccccc}
\hline Film & $\mathrm{Ax}(\mathbf{2} \% w / v)$ & $\begin{array}{c}\text { Decolorized } \\
\left(\mathrm{H}_{\mathbf{2}} \mathbf{O}_{2}\right)\end{array}$ & $\begin{array}{c}\text { Glycerol } \\
\left(\mathbf{3 0} \% w / w_{\text {Ax basis }}\right)\end{array}$ & $\begin{array}{c}\text { Citric Acid } \\
\left(\mathbf{1 0} \% w / w_{\mathrm{Ax} \text { basis }}\right)\end{array}$ & $\begin{array}{c}\text { Heat Treatment } \\
\left(\mathbf{9 0}{ }^{\circ} \mathrm{C}, \mathbf{1} \mathbf{h}\right)\end{array}$ \\
\hline 1 & $\mathrm{X}$ & & & & \\
2 & $\mathrm{X}$ & $\mathrm{X}$ & $\mathrm{X}$ & & \\
3 & $\mathrm{X}$ & $\mathrm{X}$ & $\mathrm{X}$ & $\mathrm{X}$ & \\
4 & $\mathrm{X}$ & $\mathrm{X}$ & $\mathrm{X}$ & $\mathrm{X}$ & $\mathrm{X}$ \\
5 & $\mathrm{X}$ & $\mathrm{X}$ & & \\
\hline
\end{tabular}

\subsection{Films' Characterization}

\subsubsection{Color Measurement}

The color was measured in triplicate using a colorimeter (Chroma Meter CR-300, Minolta, Tokyo, Japan), using the CIELAB or CIE $L^{*} a^{*} b^{*}$ color system. The colorimeter was calibrated against a white standard where $L^{*}=97.21, a^{*}=0.14$, and $b^{*}=1.99$, with $L^{*}$ being lightness, $a^{*}$ and $b^{*}$ being the chromaticity coordinates: $a^{*}$ from red (positive) to green 
(negative) and $b^{*}$ from yellow (positive) to blue (negative). Hue $\left(h^{\circ}\right)$, which represents the angle on the chromaticity axis, was calculated using Equations (1) and (2):

$$
h^{\circ}=\arctan \frac{b^{*}}{a^{*}} \times \frac{180}{\pi} \text { for } a^{*} \text { and } b^{*}>0
$$

or

$$
h^{\circ}=\left(\arctan \frac{b^{*}}{a^{*}} \times \frac{180}{\pi}\right)+180, \text { for } a^{*}<0
$$

Chroma $\left(C^{*}\right)$ or saturation of color was calculated by Equation (3),

$$
C^{*}=\left(\left(a^{*}\right)^{2}+\left(b^{*}\right)^{2}\right)^{\frac{1}{2}}
$$

\subsubsection{Antioxidant Activity by Ferric Reduction Antioxidant Power (FRAP) Method}

The antioxidant activity of films was determined by the FRAP method in triplicate. FRAP reagent was prepared with $25 \mathrm{~mL}$ of acetate buffer $0.3 \mathrm{M}, \mathrm{pH}=3.6,2.5 \mathrm{~mL}$ of TPTZ (2,3,5-triphenyltetrazolium chloride) solution $10 \mathrm{mM}$ in $\mathrm{HCl} 40 \mathrm{mM}$, and $2.5 \mathrm{~mL}$ of ferric chloride $20 \mathrm{mM}$. In a test tube, $270 \mu \mathrm{L}$ of deionized water, $2.7 \mathrm{~mL}$ of FRAP reagent, and around $2 \mathrm{mg}$ of film sample were added. The mixture was homogenized in a vortex (RSLAB6PRO, Auxilab S.L., Navarra, Spain) and incubated at $37^{\circ} \mathrm{C}$ in a water bath (Precision, Thermo Scientific, USA) for $30 \mathrm{~min}$. Then, the solutions were diluted in a 1:3 proportion and the absorbance was measured at $\lambda=595 \mathrm{~nm}$ (Cary $100 \mathrm{UV}$-Vis, Agilent Technologies, Santa Clara, CA, USA). A standard curve of absorbance vs. Trolox concentration was used to determine the antioxidant activity (in Trolox equivalents).

\subsubsection{Solubility}

Film solubility was determined following Ferreira et al., 2016 [20] method, with slight modifications. Samples $(10 \times 10 \mathrm{~mm})$ were cut in triplicates and dried in an oven at $50{ }^{\circ} \mathrm{C}$ for $24 \mathrm{~h}$. After this time, samples were weighed to obtain the initial dry mass $\left(m_{1}, \mathrm{~g}\right)$, then immersed in $5 \mathrm{~mL}$ of deionized water under orbital stirring (Mistral Multi-Mixer, Lab-Line Instruments, Inc., Melrose Park, IL, USA) for $24 \mathrm{~h}$. The resulting solution was centrifugated at $5000 \mathrm{rpm}$ for $5 \mathrm{~min}$ and the liquid was discarded. The solid residue was dried at $50{ }^{\circ} \mathrm{C}$ for $24 \mathrm{~h}$ and weighed to obtain the final mass $\left(m_{2}, \mathrm{~g}\right)$. Solubility was calculated using Equation (4):

$$
S(\%)=\frac{m_{1}-m_{2}}{m_{1}} \times 100
$$

\subsubsection{Mechanical Tests}

Perforation tests were carried in a TA-XT plus texturometer (Stable Micro Systems, Surrey, UK). Samples were fixed in a support with a 1-cm-diameter hole in the middle. To measure the force necessary to perforate the sample, we used a cylindrical probe with $2 \mathrm{~mm}$ of diameter, travelling at a constant velocity of $1 \mathrm{~mm} / \mathrm{sec}$. The tension of perforation $\left(\sigma_{\mathrm{p}}\right.$, $\mathrm{Pa})$ was calculated as the ratio between the perforation force $\left(F_{\mathrm{P}}, \mathrm{N}\right)$ and the circular area of the probe $\left(A_{\mathrm{c}}, \mathrm{m}^{2}\right)$. To calculate the film sample deformation during the test, we considered the radius of the support hole (initial length) as the adjacent side of a triangle rectangle and the distance travelled by the probe until the moment the film was perforated as the opposite side. The stretching length was then obtained as the hypotenuse. Deformation was calculated as the difference between the stretching length and the initial length divided by the initial length. Three film replicates were analyzed.

\subsubsection{Films' thickness and Water Vapor Permeability}

Films' thickness was measured using a digital micrometer (Digimatic Micrometer, Mitutoyo, Kawasaki, Japan). Water vapor permeability was determined gravimetrically following the method by Ferreira et al., 2016, and Serra et al., 2020 [15,20] with slight modifications. Circular film samples (diameter of $3 \mathrm{~cm}$ ) were sealed with aluminum tape on 
top of glass cups containing a saturated solution of magnesium nitrate $\left(a_{\mathrm{w}}=0.529\right)$. These glass cups were then placed in a desiccator containing a saturated solution of magnesium chloride $\left(a_{\mathrm{w}}=0.328\right)$, which was equipped with a fan to promote air circulation and to minimize the resistance of mass transfer above the film. Relative humidity and temperature were measured with a thermohygrometer (HUMICAP®HM40, Vaisala, Helsinki, Finland) in regular time intervals, as well as the weight of the cups, for $8 \mathrm{~h}$. Water vapor permeability was then calculated with Equation (5):

$$
W V P=\frac{N_{w} \times \delta}{\Delta P_{w \cdot e f f}}
$$

where $N_{\mathrm{w}}\left(\mathrm{mol} / \mathrm{m}^{2} \cdot \mathrm{s}\right)$ is the water vapor flux, $\delta(\mathrm{m})$ is the thickness of the film, and $\Delta P_{\mathrm{w}}$ eff $\mathrm{Pa}$ ) is the effective driving force, which was estimated according to the method used by Alves et al., 2010 [21]. Three film replicates were analyzed.

\subsubsection{Statistical Analysis}

Statistica 7.0 software (Statsoft Inc., Tulsa, OK, USA) was used to perform analysis of variance and post hoc Scheffe test ( $p$ level of 0.05 ) was used in order to detect differences among mean values of films' properties.

\section{Results and Discussion}

\subsection{Decolorization of Arabinoxylan Extract}

\subsubsection{Adsorption by Activated Charcoal Method}

Arabinoxylan was decolorized with activated charcoal at two different concentrations of $0.5 \%$ and $2 \%\left(w_{\text {activated charcoal }} / v_{\text {solution }}\right)$ for $1 \mathrm{~h}$ at room temperature. Absorbance spectra were measured before and after the addition of activated charcoal and are presented below (Figures 1 and 2).

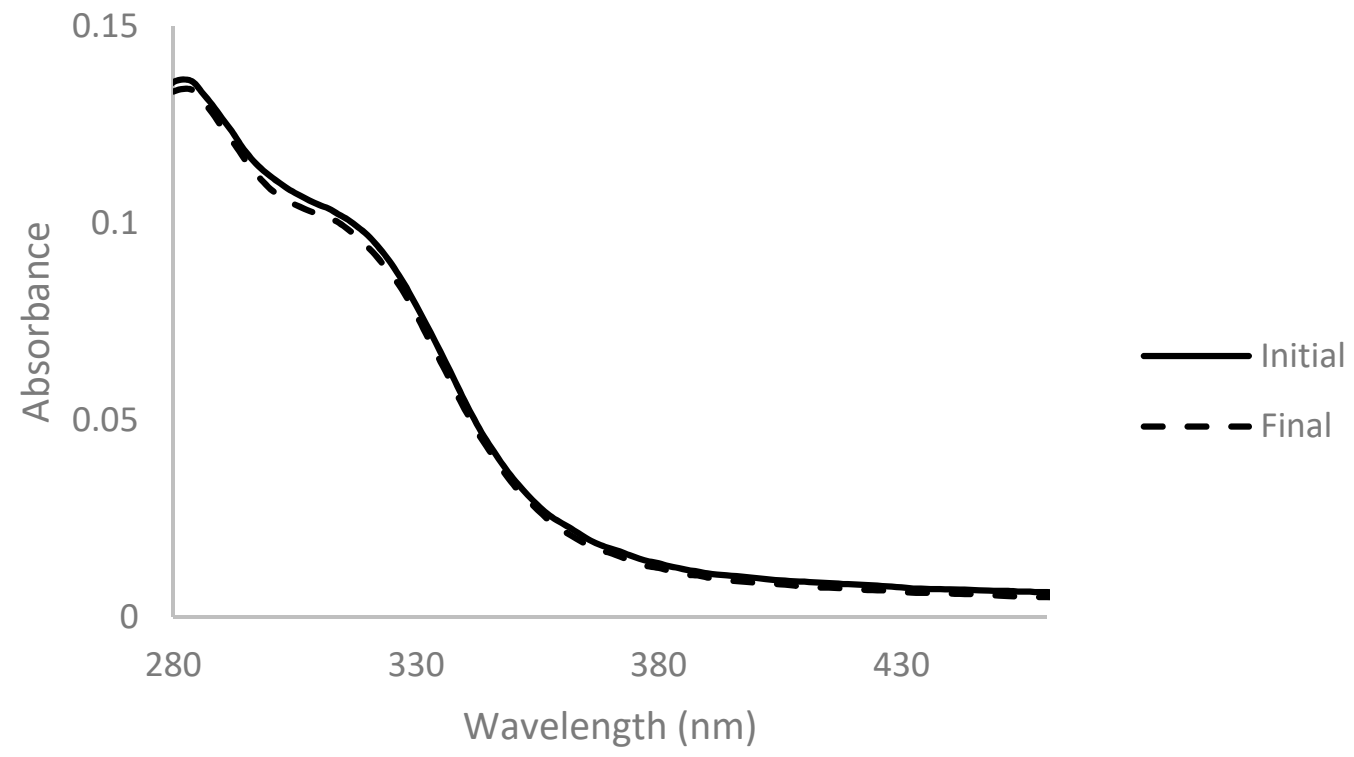

Figure 1. Absorbance spectra of arabinoxylan extract with $0.5 \%(w / v)$ of activated charcoal before (full line) and after $1 \mathrm{~h}$ of contact (dashed line), for a dilution ratio of 1:200. 


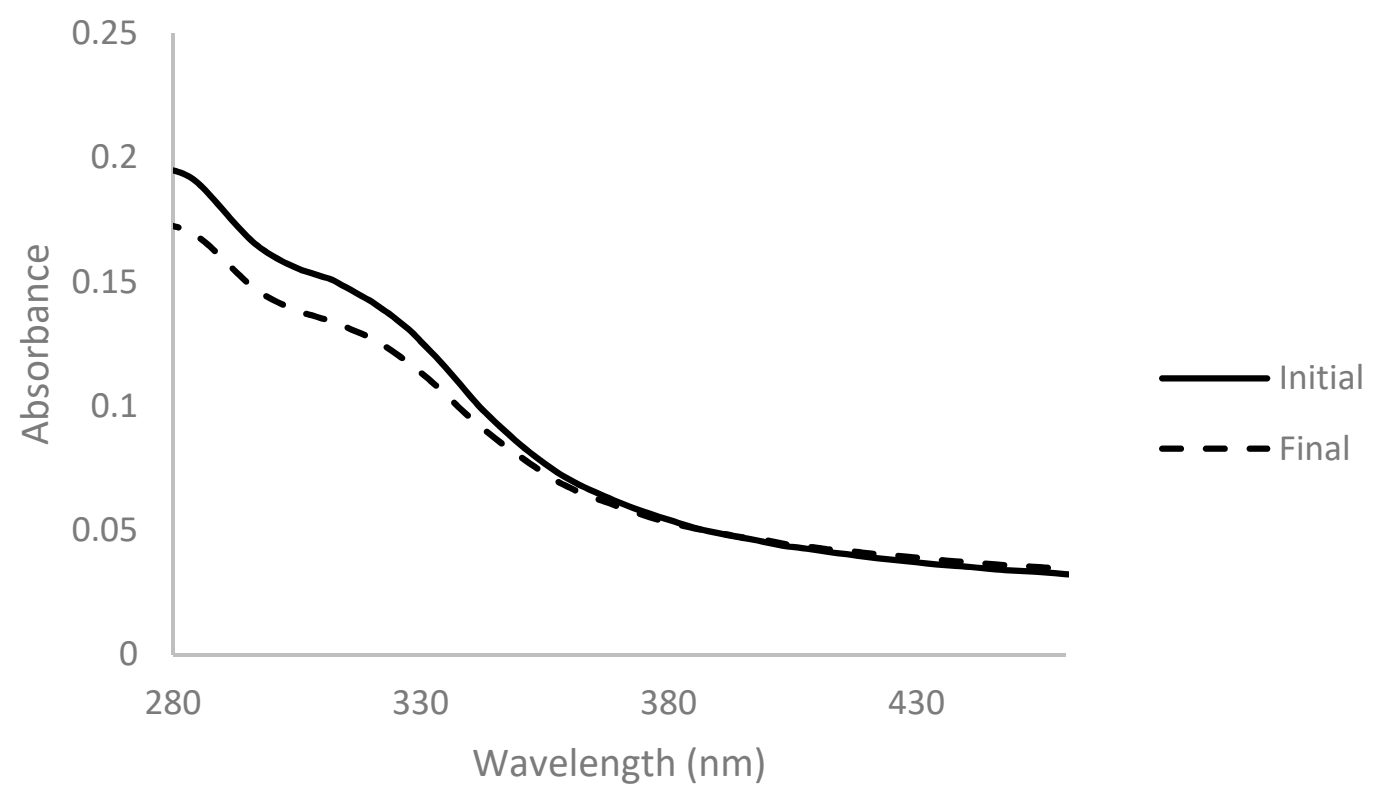

Figure 2. Absorbance spectra of arabinoxylan extract with $2 \%(w / v)$ of activated charcoal before (full line) and after $1 \mathrm{~h}$ of contact (dashed line), for a dilution ratio of 1:200.

The spectrum obtained with $2 \%$ activated charcoal showed a more accentuated decrease in absorbance after the addition when compared with the spectrum with only $0.5 \%$. This change indicates that the activated charcoal was able to adsorb components present in the solution to some extent. However, the color of the solution did not change when observed at naked eye in both cases (Figure 3).
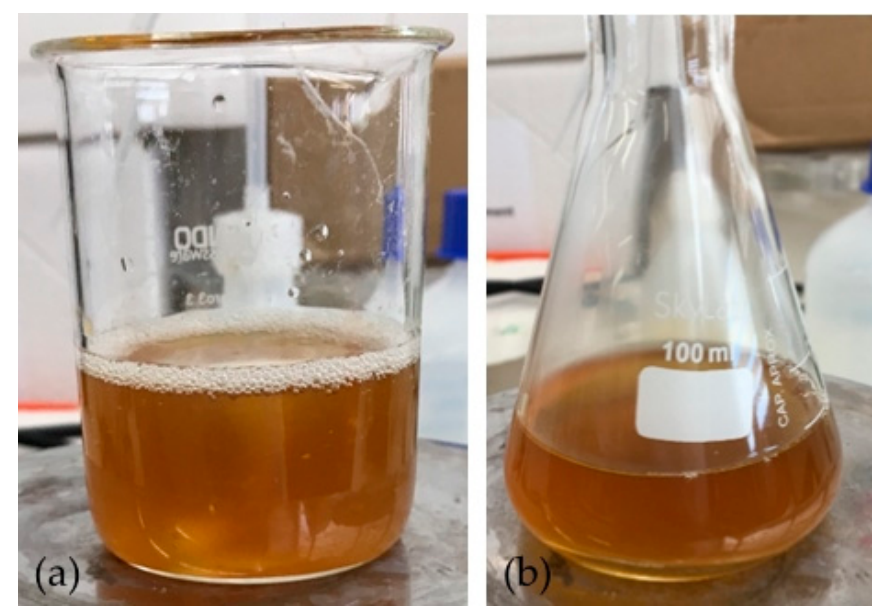

Figure 3. Solution of arabinoxylan $(2 \% w / v)$ : (a) before the addition of activated charcoal $(2 \% w / v)$ and (b) after $1 \mathrm{~h}$ of contact.

\subsubsection{Hydrogen Peroxide Method}

Another method was tested for the decolorization of arabinoxylan, employing hydrogen peroxide. A solution of $2 \%(w / v)$ of arabinoxylan was prepared, and hydrogen peroxide in a concentration of $10 \%\left(v / v_{\text {final }}\right)$ was added. Absorbance spectra were measured before and after the addition and are presented below (Figure 4). 


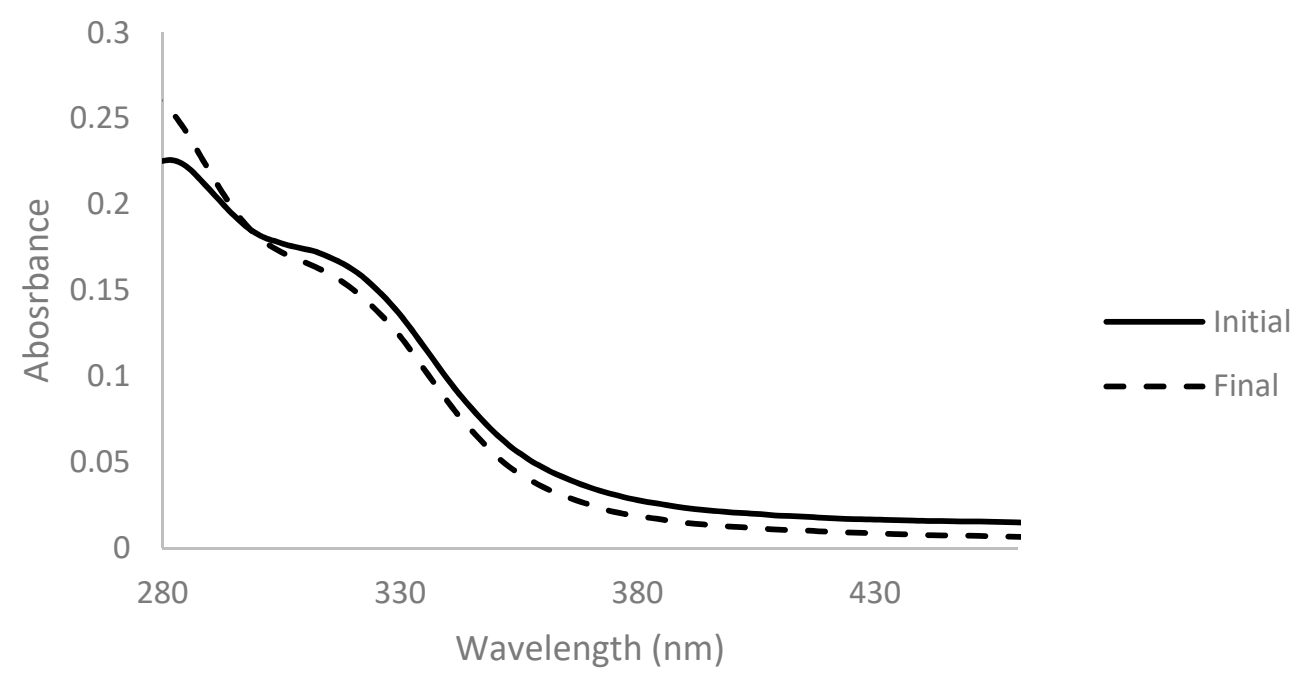

Figure 4. Absorbance spectra of arabinoxylan $2 \%(w / v)$ with $10 \%\left(v / v_{\text {final }}\right)$ of hydrogen peroxide before (full line) and after $2 \mathrm{~h}$ of reaction time at $45^{\circ} \mathrm{C}$ (dashed line), for a dilution ratio of 1:100.

A lower absorbance of the solution in the 300-nm-onwards zone of the spectrum after reaction was noticed. This change was complemented with a change of the color of the solution, which shifted from a darker and brownish color to a lighter and yellow color (Figure 5).

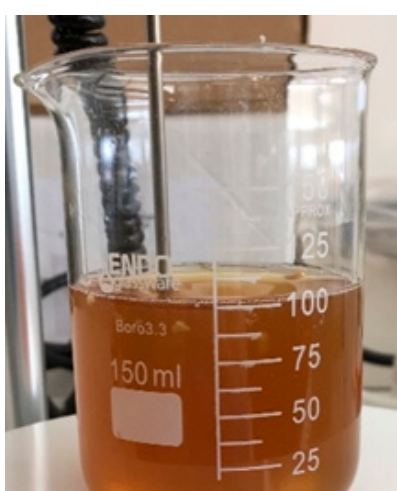

(a)

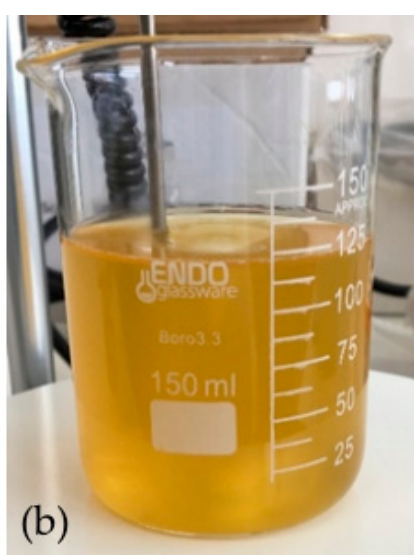

(a) before the addition of hydrogen peroxide Figure 5. Solution of arabinoxylan $(2 \% w / v):$ (a) b
$\left(10 \% v / v_{\text {final }}\right)$ and $(\mathbf{b})$ after $2 \mathrm{~h}$ at $45^{\circ} \mathrm{C}$ of reaction time.

Additionally, a higher hydrogen peroxide concentration $\left(20 \% v / v_{\text {final }}\right)$ and reaction time $(5.5 \mathrm{~h})$ were also tested. However, no significant improvement in the color of the solution was noted. Therefore, considering the results obtained above, the decolorization process continued with the hydrogen peroxide method as described in Section 2.2.

\subsection{Films' Characterization}

\subsubsection{Color Measurement}

The color of films was measured, as described in Section 2.4.1, and the results are summarized in Table 2.

The hue values calculated, around $89^{\circ}$ and $100^{\circ}$ for non-decolorized and decolorized films, respectively, indicated decolorized films presenting a color closer to a light-yellow, and films without decolorization a tonality close to dark yellow-orange, consistent with the images of Figure 6. 
Table 2. Values of lightness $\left(L^{*}\right)$, chromaticity coordinates $\left(a^{*}, b^{*}\right)$, and the calculated hue $\left(h^{\circ}\right)$ and chroma $\left(C^{*}\right)$ for the arabinoxylan films obtained. Values in the same column followed by different superscript letters differ significantly $(p<0.05)$.

\begin{tabular}{|c|c|c|c|c|c|}
\hline Film & $L^{*}$ & $a^{*}$ & $b^{*}$ & $h^{\circ}$ & $C^{*}$ \\
\hline $1(\mathrm{Ax})$ & $80.29 \pm 0.69^{a}$ & $0.65 \pm 0.32^{a}$ & $43.60 \pm 1.21^{\mathrm{a}}$ & $89.15 \pm 0.40^{a}$ & $43.60 \pm 1.21^{a}$ \\
\hline $2($ Ax + Glycerol $)$ & $79.65 \pm 0.99^{a}$ & $0.56 \pm 0.48^{\mathrm{a}}$ & $46.85 \pm 1.90^{b}$ & $89.33 \pm 0.57^{a}$ & $46.86 \pm 1.91^{b}$ \\
\hline $3\left(\mathrm{Ax}+\mathrm{H}_{2} \mathrm{O}_{2}+\right.$ Glycerol $)$ & $95.64 \pm 0.24^{b}$ & $-1.77 \pm 0.17^{b}$ & $8.69 \pm 0.64^{c}$ & $101.48 \pm 0.23^{b}$ & $8.87 \pm 0.66^{\mathrm{c}}$ \\
\hline $4\left(\mathrm{Ax}+\mathrm{H}_{2} \mathrm{O}_{2}+\right.$ Glycerol + Citric Acid $)$ & $94.94 \pm 0.23^{b}$ & $-2.62 \pm 0.19^{c}$ & $14.56 \pm 1.00^{\mathrm{d}}$ & $100.19 \pm 0.24^{b}$ & $14.79 \pm 1.01^{\mathrm{d}}$ \\
\hline $5\left(\mathrm{Ax}+\mathrm{H}_{2} \mathrm{O}_{2}+\right.$ Glycerol + Citric Acid $\left.+90^{\circ} \mathrm{C}, 1 \mathrm{~h}\right)$ & $89.03 \pm 0.88^{c}$ & $-1.55 \pm 0.10^{b}$ & $28.04 \pm 1.00^{\mathrm{e}}$ & $93.16 \pm 0.29^{c}$ & $28.08 \pm 0.99 \mathrm{e}$ \\
\hline
\end{tabular}
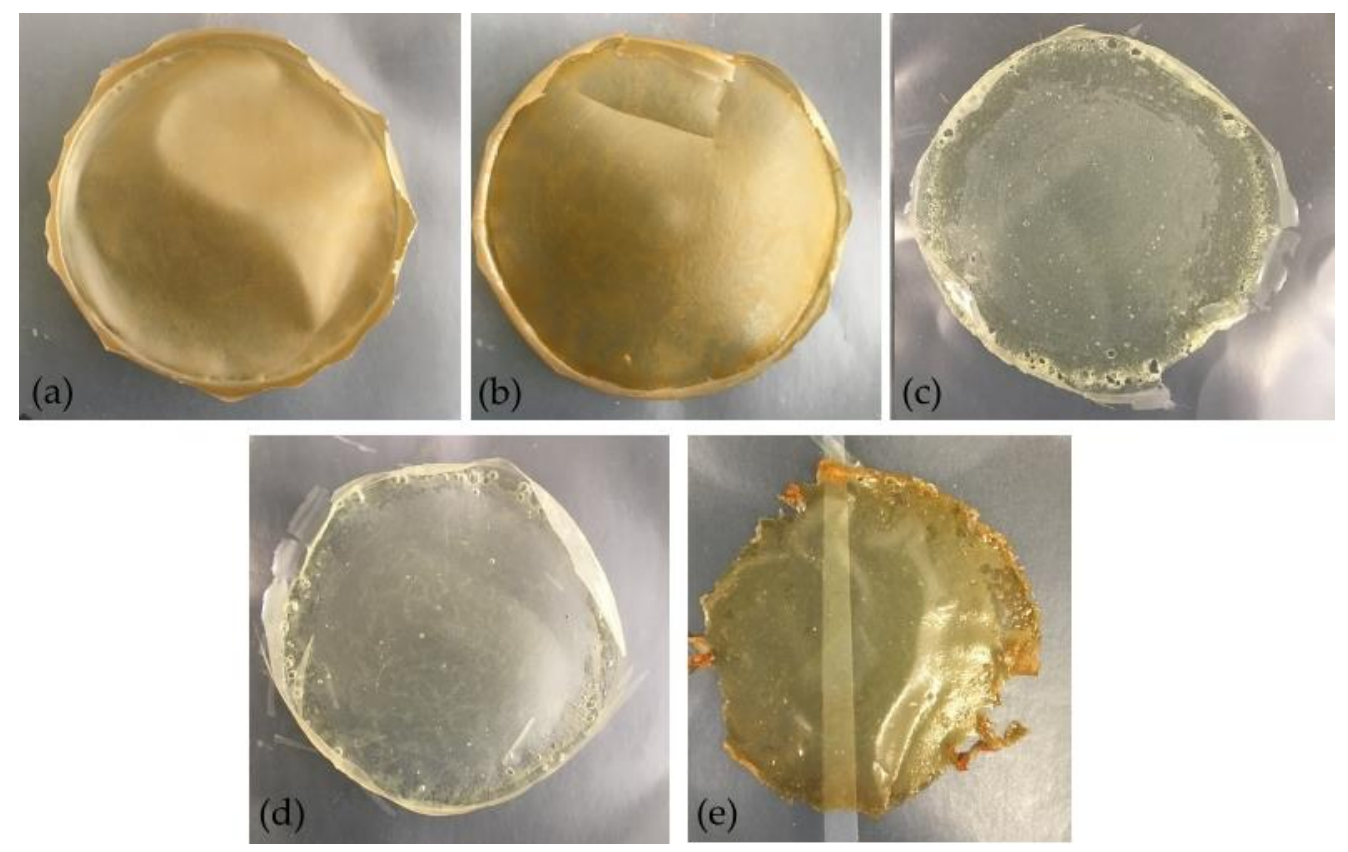

Figure 6. Films based on arabinoxylan (Ax): (a) 1 (Ax), (b) 2 (Ax + Glycerol), (c) $3\left(\mathrm{Ax}+\right.$ Glycerol $\left.+\mathrm{H}_{2} \mathrm{O}_{2}\right)$, (d) 4 (Ax + Glycerol $+\mathrm{H}_{2} \mathrm{O}_{2}+$ Citric Acid), and (e) 5 (Ax + Glycerol $+\mathrm{H}_{2} \mathrm{O}_{2}+$ Citric Acid $\left.+90{ }^{\circ} \mathrm{C}, 1 \mathrm{~h}\right)$.

The non-decolorized arabinoxylan films prepared in a previous work [15], with 30\% glycerol $\left(w / w_{\text {dry basis }}\right)$, presented hue values $\left(h^{\circ}=86.64 \pm 1.28\right)$ similar to those of this work. In addition to hue, color saturation $\left(C^{*}\right)$ also changed substantially when applying the decolorization method, decreasing to values around 9 and 15 . The results showed that, even though full transparency was not obtained when applying decolorization, a more pleasant light-yellow color could be achieved.

The film that was subjected to heat treatment presented color values in between the two mentioned above. Since it did not bring positive results in terms of color, this method was discarded.

\subsubsection{Antioxidant Activity}

Antioxidant activity was determined by the FRAP method, by dissolving film samples directly in the FRAP reagent. Results are presented below (Table 3).

Films were expected to show antioxidant activity due to the presence of ferulic acid and other molecules, which were released during the arabinoxylan alkaline extraction from corn fiber and remained in the extract after its purification with membrane processes $[13,15]$.

According to the results, the addition of other components than arabinoxylan while preparing the filmogenic solutions appeared to slightly reduce the antioxidant activity of the resulting films. The major decrease was noticed when the films were produced from decolorized purified extract. This fact may be attributed to the antioxidant's reaction with $\mathrm{H}_{2} \mathrm{O}_{2}$, applied with the intention of removing colored substances. An arabinoxylan film previously prepared in a previous work with the same formulation as 2 (Arabinoxylan with $30 \% w / w_{\text {Ax basis }}$ of glycerol) showed an antioxidant activity of $(1.56 \pm 0.85) \times 10^{-5} \mathrm{mmol}$ 
Trolox/mg film [15]. All films prepared in this work showed a higher value, which can be due to differences in the composition of the purified arabinoxylan among the different batches produced, more specifically regarding the quantity of ferulic acid present.

Table 3. Antioxidant activity of films obtained expressed as Trolox equivalents ( $\mathrm{mmol}$ Trolox/mg film). Values in the same column followed by different superscript letters differ significantly $(p<0.05)$.

\begin{tabular}{cc}
\hline Film & $\begin{array}{c}\text { Antioxidant Activity } \\
\left(\mathbf{1 0}^{-\mathbf{5}} \mathbf{~} \mathbf{m} \text { mol Trolox/mg Film }\right)\end{array}$ \\
\hline $1(\mathrm{Ax})$ & $5.09 \pm 0.14^{\mathrm{a}}$ \\
$2(\mathrm{Ax}+\mathrm{Glycerol})$ & $4.15 \pm 0.46^{\mathrm{b}}$ \\
$3\left(\mathrm{Ax}+\mathrm{H}_{2} \mathrm{O}_{2}+\right.$ Glycerol $)$ & $3.53 \pm 0.39^{\mathrm{b}, \mathrm{c}}$ \\
$4\left(\mathrm{Ax}+\mathrm{H}_{2} \mathrm{O}_{2}+\right.$ Glycerol + Citric Acid $)$ & $3.21 \pm 0.40^{\mathrm{c}}$ \\
\hline
\end{tabular}

\subsubsection{Films' Cross-Linking and Solubility in Water}

The values of films' solubility in water are presented in Table 4.

Table 4. Solubility in water (\%) of arabinoxylan films obtained. Values in the same column followed by different superscript letters differ significantly $(p<0.05)$.

\begin{tabular}{cc}
\hline Film & Solubility (\%) \\
\hline $1(\mathrm{Ax})$ & $86 \pm 10^{\mathrm{a}}$ \\
$2(\mathrm{Ax}+\mathrm{Glycerol})$ & $87 \pm 10^{\mathrm{a}}$ \\
$3\left(\mathrm{Ax}+\mathrm{H}_{2} \mathrm{O}_{2}+\right.$ Glycerol $)$ & $70 \pm 13^{\mathrm{a}}$ \\
$4\left(\mathrm{Ax}+\mathrm{H}_{2} \mathrm{O}_{2}+\right.$ Glycerol + Citric Acid $)$ & $82 \pm 10^{\mathrm{a}}$ \\
\hline
\end{tabular}

It can be observed that all films were highly soluble in water. It appears that the decolorization process did not significantly change the hydrophilic nature of arabinoxylan polymeric matrix. In addition, the performance of citric acid as a cross-linker under the conditions tested was not effective, as the solubility in water of cross-linked and noncross-linked films was not significantly different. The cross-linking reaction expected was esterification, which is not very favorable in an aqueous medium [22]. However, due to the nature of the extract (insoluble in most solvents), it was difficult to carry the reaction in different media besides water. When comparing with other polysaccharides, FucoPol and chitosan films presented a quite lower solubility in water $(47.5 \pm 5.2 \%$ and $30.5 \pm 0.5 \%$, respectively) [20] than the produced films in this work.

\subsubsection{Water Vapor Permeability}

The water vapor permeability values, determined by the gravimetric method described in Section 2.4.5, are presented in Table 5.

Table 5. Water vapor permeability (WVP) $\left(10^{-11} \mathrm{~mol} \cdot \mathrm{m} / \mathrm{m}^{2} \cdot \mathrm{s} \cdot \mathrm{Pa}\right)$ and thickness $(\mu \mathrm{m})$ of arabinoxylan films tested. Values in the same column followed by different superscript letters differ significantly $(p<0.05)$.

\begin{tabular}{ccc}
\hline Film & Thickness $(\boldsymbol{\mu m})$ & WVP $\left._{\mathbf{1 0}} \mathbf{1 0}^{\mathbf{1 1}} \mathbf{~} \mathbf{m o l} \cdot \mathbf{m} / \mathbf{m}^{\mathbf{2}} \cdot \mathbf{s} \cdot \mathbf{P a}\right)$ \\
\hline $1(\mathrm{Ax})$ & $76 \pm 6$ & $3.89 \pm 1.99^{\mathrm{a}}$ \\
$2(\mathrm{Ax}+\mathrm{Glycerol})$ & $101 \pm 12$ & $2.62 \pm 0.96^{\mathrm{a}}$ \\
$3\left(\mathrm{Ax}+\mathrm{H}_{2} \mathrm{O}_{2}+\right.$ Glycerol $)$ & $79 \pm 2$ & $3.46 \pm 0.13^{\mathrm{a}}$ \\
$4\left(\mathrm{Ax}+\mathrm{H}_{2} \mathrm{O}_{2}+\right.$ Glycerol + Citric Acid $)$ & $94 \pm 3$ & $2.94 \pm 0.49^{\mathrm{a}}$ \\
\hline
\end{tabular}

Due to the hydrophilic nature of arabinoxylan, we expected a low water vapor barrier of the tested films. The addition of glycerol or any plasticizer is usually followed by an increase of WVP since these molecules incorporated in the polysaccharide matrix decrease the molecular density and consequently increase the water vapor diffusion. However, in 
this work, the glycerol addition was not reflected significantly in the results obtained, since the WVP values were quite similar between the different film formulations.

When comparing with an arabinoxylan film with $15 \%\left(w / w_{\text {Ax basis }}\right)$ of glycerol [23], with a value of WVP $=(0.98 \pm 0.03) \times 10^{-11} \mathrm{~mol} \cdot \mathrm{m} / \mathrm{m}^{2} \cdot \mathrm{s} \cdot \mathrm{Pa}$ (driving force $\left.84-22 \%, \mathrm{RH}(\%)\right)$, it may be seen that the produced film in the present work with a higher content of glycerol (Ax + Glycerol $\left.30 \% w / w_{\text {Ax basis }}\right)$ did have a higher value of water vapor permeability. However, when compared with another arabinoxylan film prepared in a different work, with the same glycerol content $\left(W V P=(0.62 \pm 0.02) \times 10^{-11} \mathrm{~mol} \cdot \mathrm{m} / \mathrm{m}^{2} \cdot \mathrm{s} \cdot \mathrm{Pa}\right.$, driving force 52.9-32.8\%, $\mathrm{RH}(\%))(5)$, the equivalent film prepared in this work had a higher WVP value $\left(\mathrm{WVP}=(2.62 \pm 0.96) \times 10^{-11} \mathrm{~mol} \cdot \mathrm{m} / \mathrm{m}^{2} \cdot \mathrm{s} \cdot \mathrm{Pa}\right)$. This behavior can be explained by differences in the composition of the arabinoxylan extract, purification methods, and casting and drying conditions that alter the state of the resulting film.

Comparing values of water vapor permeability of other polysaccharide films like FucoPol $\left(\mathrm{WVP}=(0.75 \pm 0.05) \times 10^{-11} \mathrm{~mol} \cdot \mathrm{m} / \mathrm{m}^{2} \cdot \mathrm{s} \cdot \mathrm{Pa}\right.$, driving force $\left.76.9-22.5 \%, \mathrm{RH}(\%)\right)$, it may be seen that the present films show a higher permeability. However, when compared with films from chitosan $\left(\mathrm{WVP}=(4.13 \pm 0.13) \times 10^{-11} \mathrm{~mol} \cdot \mathrm{m} / \mathrm{m}^{2} \cdot \mathrm{s} \cdot \mathrm{Pa}\right.$, driving force 76.9-22.5\%, $\mathrm{RH}(\%)$ ), some of the obtained films in this work showed a lower water vapor permeability. It is also important to mention that WVP is highly dependent on the driving force used, in addition to the other variables mentioned above [20].

\subsubsection{Mechanical Tests}

Perforation tests were carried out in quadruplicate and the mechanical parameters measured are presented in Table 6.

Table 6. Tension of perforation (MPa), deformation (\%), and thickness ( $\mu \mathrm{m})$ of arabinoxylan films. Values in the same column followed by different superscript letters differ significantly $(p<0.05)$.

\begin{tabular}{cccc}
\hline Film & Thickness $(\boldsymbol{\mu m})$ & $\begin{array}{c}\text { Tension of } \\
\text { Perforation (MPa) }\end{array}$ & Deformation (\%) \\
\hline $1(\mathrm{Ax})$ & $79 \pm 6$ & $1.17 \pm 0.23^{\mathrm{a}}$ & $1.3 \pm 0.3^{\mathrm{a}}$ \\
$2(\mathrm{Ax}+\mathrm{Glycerol})$ & $84 \pm 4$ & $2.36 \pm 0.30^{\mathrm{b}}$ & $50.8 \pm 4.8^{\mathrm{b}}$ \\
$3\left(\mathrm{Ax}+\mathrm{H}_{2} \mathrm{O}_{2}+\right.$ Glycerol $)$ & $89 \pm 11$ & $1.57 \pm 0.15^{\mathrm{a}}$ & $41.3^{\mathrm{a}} \pm 3.1^{\mathrm{c}}$ \\
$4\left(\mathrm{Ax}+\mathrm{H}_{2} \mathrm{O}_{2}+\right.$ Glycerol + Citric Acid & $105 \pm 19$ & $1.22 \pm 0.41^{\mathrm{a}}$ & $53.0 \pm 1.7^{\mathrm{b}}$ \\
\hline
\end{tabular}

The film sample produced only with arabinoxylan (Ax) presented a brittle, non-ductile structure evidenced by the rather low deformation upon perforation $(1.3 \pm 0.3 \%)$. The need for using a plasticizer is evidenced by the higher mechanical resistance achieved when glycerol was added to the formulation (Ax + Glycerol), with a substantial increase of tension and deformation upon perforation $(2.36 \pm 0.3 \mathrm{MPa}$ and $50.8 \pm 4.8 \%$, respectively). An arabinoxylan film from maize bran with $25 \%$ of glycerol in its composition showed a value tension of perforation of $2.42 \pm 0.12 \mathrm{MPa}$ [16], which is very similar to that of the prepared film in this work with $30 \%$ of glycerol.

The addition of $\mathrm{H}_{2} \mathrm{O}_{2}$ for decolorization led to films with lower tension of perforation, while maintaining a substantial deformation $(41.3 \pm 3.1 \%$ and $53.0 \pm 1.7 \%$ for films 3 and 4 , respectively). As such, the results envisage the maintenance of suitable mechanical properties for decolorized film samples.

\section{Conclusions}

The decolorization of a purified arabinoxylan extract from corn fiber was achieved using hydrogen peroxide as decolorizing agent. This process originated a more appealing light-yellow solution that retained its film-forming properties. Decolorized films of arabinoxylan were prepared with glycerol as plasticizer and citric acid as cross-linker. Though the cross-linking reaction was not successful, since the film incorporated with citric acid still presented a high solubility in water, films showed promising properties. Decolorized films with glycerol and citric acid retained a significant antioxidant activity, and values of water 
vapor permeability were similar to that of non-decolorized ones and other polysaccharides. In addition, the decolorization process did not affect substantially the films' mechanical properties under perforation tests.

New strategies are necessary to improve the conditions for cross-linking reactions, by either changing the solvent or choosing a different cross-linker. To improve the properties of resulting films, arabinoxylan blends with other polysaccharides or biopolymers with hydrophobic nature are envisaged.

Author Contributions: Conceptualization: V.W., C.B., I.M.C. and V.D.A.; methodology: V.W., C.B., I.M.C. and V.D.A.; investigation: V.W., C.B., I.M.C. and V.D.A.; resources: C.B., I.M.C. and V.D.A.; data curation, V.W.; writing-original draft preparation: V.W.; writing-review and editing: V.W., C.B., I.M.C. and V.D.A.; supervision: C.B., I.M.C. and V.D.A.; project administration, C.B.; funding acquisition: C.B., I.M.C. and V.D.A. All authors have read and agreed to the published version of the manuscript.

Funding: This research was supported by the Associate Laboratory for Green Chemistry-LAQV and LEAF_LLinking Landscape, Environment, Agriculture and Food research unit, which are financed by national funds from FCT/MCTES (UIDB/50006/2020, UIDP/50006/2020 and UID/AGR/04129/2020). This research was also funded by the iBET's funding program iBETXplore, through the project entitled "BioXOSAX, Characterization of xylo-oligosaccharides XOS and arabinoxylans AX: new biopolymers from starch by-product for food and pharma applications." This research was also funded by SOCIEDADE PONTO VERDE-SOCIEDADE GESTORA DE RESÍDUOS DE EMBALAGENS, S.A., through the project entitled "Bioplastics and Edible, Vegan Films".

Institutional Review Board Statement: Not applicable.

Informed Consent Statement: Not applicable.

Data Availability Statement: Not applicable.

Acknowledgments: The authors would like to acknowledge the company Copam-Companhia Portuguesa de Amidos, S.A. for providing corn fiber to prepare the raw material of this work.

Conflicts of Interest: The authors declare no conflict of interest.

\section{References}

1. Yadav, A.; Mangaraj, S.; Singh, R.; Das, K.; Kumar, N.; Arora, S. Biopolymers as Packaging Material in Food and Allied Industry. Int. J. Chem. Stud. 2018, 6, 2411-2418.

2. RameshKumar, S.; Shaiju, P.; O'Connor, K.E. Bio-Based and Biodegradable Polymers-State-of-the-Art, Challenges and Emerging Trends. Curr. Opin. Green Sustain. Chem. 2020, 21, 75-81. [CrossRef]

3. Ferreira, A.R.V.; Alves, V.D.; Coelhoso, I.M. Polysaccharide-Based Membranes in Food Packaging Applications. Membranes 2016, 6, 22. [CrossRef]

4. Kliem, S.; Kreutzbruck, M.; Bonten, C. Review on the Biological Degradation of Polymers in Various Environments. Materials 2002, 3, 632-640. [CrossRef]

5. Dharmalingam, K.; Anandalakshmi, R. Polysaccharide-Based Films for Food Packaging Applications; Springer: Singapore, 2019; pp. 183-207.

6. Cazón, P.; Velazquez, G.; Ramírez, J.A.; Vázquez, M. Polysaccharide-Based Films and Coatings for Food Packaging: A Review. Food Hydrocoll. 2017, 68, 136-148. [CrossRef]

7. Vartiainen, J.; Vähä-Nissi, M.; Harlin, A. Biopolymer Films and Coatings in Packaging Applications-A Review of Recent Developments. Mater. Sci. Appl. 2014, 05, 708-718. [CrossRef]

8. Mendes, J.F.; Norcino, L.B.; Manrich, A.; Pinheiro, A.C.M.; Oliveira, J.E.; Mattoso, L.H.C. Characterization of Pectin Films Integrated with Cocoa Butter by Continuous Casting: Physical, Thermal and Barrier Properties. J. Polym. Environ. 2020, 28, 2905-2917. [CrossRef]

9. Huang, L.; Xu, H.; Zhao, H.; Xu, M.; Qi, M.; Yi, T.; An, S.; Zhang, X.; Li, C.; Huang, C.; et al. Properties of Thermoplastic Starch Films Reinforced with Modified Cellulose Nanocrystals Obtained from Cassava Residues. New J. Chem. 2019, 43, 14883-14891. [CrossRef]

10. Kaya, M.; Khadem, S.; Cakmak, Y.S.; Mujtaba, M.; Ilk, S.; Akyuz, L.; Salaberria, A.M.; Labidi, J.; Abdulqadir, A.H.; Deligöz, E. Antioxidative and Antimicrobial Edible Chitosan Films Blended with Stem, Leaf and Seed Extracts of Pistacia Terebinthus for Active Food Packaging. RSC Adv. 2018, 8, 3941-3950. [CrossRef]

11. Ferreira, A.R.V.; Torres, C.A.V.; Freitas, F.; Reis, M.A.M.; Vítor, D.; Coelhoso, I.M. Biodegradable Films Produced from the Bacterial Polysaccharide FucoPol. Int. J. Biol. Macromol. 2014, 71, 111-116. [CrossRef] 
12. Pires, J.; de Paula, C.D.; Souza, V.G.L.; Fernando, A.L.; Coelhoso, I. Understanding the Barrier and Mechanical Behavior of Different Nanofillers in Chitosan Films for Food Packaging. Polymers 2021, 13, 721. [CrossRef]

13. Rose, D.J.; Inglett, G.E.; Liu, S.X. Utilisation of Corn (Zea mays) Bran and Corn Fiber in the Production of Food Components. J. Sci. Food Agric. 2010, 90, 915-924. [CrossRef] [PubMed]

14. Saeed, F.; Hussain, M.; Arshad, M.S.; Afzaal, M.; Munir, H.; Imran, M.; Tufail, T.; Anjum, F.M. Functional and Nutraceutical Properties of Maize Bran Cell Wall Non-Starch Polysaccharides. Int. J. Food Prop. 2021, 24, 233-248. [CrossRef]

15. Serra, M.; Weng, V.; Coelhoso, I.M.; Alves, V.D.; Brazinha, C. Purification of Arabinoxylans from Corn Fiber and Preparation of Bioactive Films for Food Packaging. Membranes 2020, 10, 95. [CrossRef]

16. Anderson, C.; Simsek, S. Mechanical Profiles and Topographical Properties of Films Made from Alkaline Extracted Arabinoxylans from Wheat Bran, Maize Bran, or Dried Distillers Grain. Food Hydrocoll. 2019, 86, 78-86. [CrossRef]

17. Zhurlova, O.D. The Current Trends and Future Perspectives of Arabinoxylans Prebiotics Research: А Rеviеw. ЗерновіПродукти I Комбікорми 2017, 17, 4-11. [CrossRef]

18. Mendez-Encinas, M.A.; Carvajal-Millan, E.; Rascon-Chu, A.; Astiazaran-Garcia, H.F.; Valencia-Rivera, D.E. Ferulated Arabinoxylans and Their Gels: Functional Properties and Potential Application as Antioxidant and Anticancer Agent. Oxid. Med. Cell. Longev. 2018, 2018. [CrossRef]

19. Anderson, C.; Simsek, S. A Novel Combination of Methods for the Extraction and Purification of Arabinoxylan from Byproducts of the Cereal Industry. J. Food Meas. Charact. 2019, 13, 1049-1057. [CrossRef]

20. Ferreira, A.R.V.; Torres, C.A.V.; Freitas, F.; Sevrin, C.; Grandfils, C.; Reis, M.A.M.; Alves, V.D.; Coelhoso, I.M. Development and Characterization of Bilayer Films of FucoPol and Chitosan. Carbohydr. Polym. 2016, 147, 8-15. [CrossRef] [PubMed]

21. Alves, V.D.; Costa, N.; Coelhoso, I.M. Barrier Properties of Biodegradable Composite Films Based on Kappa-Carrageenan/Pectin Blends and Mica Flakes. Carbohydr. Polym. 2010, 79, 269-276. [CrossRef]

22. Liu, Y.; Lotero, E.; Goodwin, J.G. Effect of Water on Sulfuric Acid Catalyzed Esterification. J. Mol. Catal. A Chem. 2006, 245, 132-140. [CrossRef]

23. Péroval, C.; Debeaufort, F.; Despré, D.; Voilley, A. Edible Arabinoxylan-Based Films. 1. Effects of Lipid Type on Water Vapor Permeability, Film Structure, and Other Physical Characteristics. J. Agric. Food Chem. 2002, 50, 3977-3983. [CrossRef] 